\title{
ICT Industry Certification: Integration Issues for Post- Secondary Educational Institutions in Australia
}

\author{
Terry W Koziniec and Michael W Dixon \\ Murdoch University, Perth, Australia
}

\author{
t.koziniec@murdoch.edu.au m.dixon@murdoch.edu.au
}

\begin{abstract}
Driven by the incredible pace of technological change the Information and Communication Technology (ICT) vendors have led the charge in promoting industry based technical certifications. Today, there are a plethora of instructor led, intensive, short courses that provide training in an ICT vendor's product and prepare participants to sit a certification exam. Increasingly, vendors are developing expanded certification programs suitable for inclusion in high school, college and university courses. Although these programs are attractive to students and educational institutions, there are obstacles to be overcome and risks to be evaluated when attempting to integrate a certification program within a traditional offering. This paper examines these issues in detail.
\end{abstract}

Keywords: Industry certification, Information and Communication Technology, Training, Education

\section{Introduction}

Driven by the incredible pace of technological change and the desire of Information and Communication Technology (ICT) vendors to provide a strong technical support base for their products, the ICT sector has led the charge in promoting industry based technical certifications. Today, there are a plethora of instructor led, intensive, short courses that provide training in an ICT vendor's product and prepare participants to sit a certification exam. Vendors with established certification programs include Adobe, Cisco Systems, IBM, Microsoft, Red Hat, Sun Micro Systems, Novell and the Computing Technology Industry Association (CompTIA).

Initially, ICT industry training and certification programs were aimed at providing specific skills for individuals already supporting software and hardware systems in the information technology industry. More recently, the shortage of skilled ICT workers (Deloitte Touche Tohmatsu, 2000) has led to industry certification programs designed for delivery in high schools, Tertiary and Further Education (TAFE) institutions and universities. For companies who dominate their market such as Microsoft and Cisco Systems, the payoffs in developing such programs are as much about increasing the size of the market as they are about increasing their share of the market. For educational institutions these programs offer an attractive combination of internationally recognised certifications, professional teaching resource materials, industry association and targeted marketing possibilities.

This paper examines the pertinent issues and obstacles encountered when considering the integration of an

Material published as part of these proceedings, either on-line or in print, is copyrighted by Informing Science. Permission to make digital or paper copy of part or all of these works for personal or classroom use is granted without fee provided that the copies are not made or distributed for profit or commercial advantage AND that copies 1) bear this notice in full and 2) give the full citation on the first page. It is permissible to abstract these works so long as credit is given. To copy in all other cases or to republish or to post on a server or to redistribute to lists requires specific permission from the publisher at publister@intormingscience.org
ICT certification within an educational institution's existing awards.

\section{Certification in Other Professions}

There has long been debate over the difference and relative merits of training versus education. While medical, legal and accounting academics have accepted certification as part of their profession, in- 
ICT Industry Certification

formation technology academics have been reluctant to do so (Ray \& McCoy, 2000). In fairness the differences between the aforementioned certifications and ICT certifications explain this reticence. In particular, medical, legal and accounting certifications are promoted by independent professional bodies, while certifications in the ICT sector are, with the exception of the CompTIA, promoted by individual corporate vendors. The symbolism also differs. In other professions, certification is seen as a right of passage into that profession and as an entry requirement for membership of the relevant professional body. For example, passing the Institute of Chartered Accountants Professional Year program allows a graduate to become a member of the Institute of Chartered Accountants and to use the designation 'Chartered Accountant'. In contrast, an ICT certification symbolises a technical specialisation and proficiency that is quite separate to the membership requirements of professional bodies such as the Australian Computer Society or the Institute of Electrical and Electronic Engineers. Despite these differences, ICT certifications share several characteristics with other professional certification, they are:

- Almost universally recognised

- Focused on the perceived needs of the industry

- The skills associated with accreditation are clearly identifiable and valued by potential employers.

\section{Paths to Certification}

Industry certification is normally obtained after passing one or more computer based exams administered by the vendor or, more commonly, an independent testing agency. Relatively few industry certifications involve the actual configuration of software or equipment. The notable exception is the notoriously difficult Cisco Certified Internet Expert (CCIE) laboratory exam. Vendors do not usually require any evidence of training and candidates are free to choose how they prepare for their exam. Typically candidates prepare in one of the following ways:

- Attending an intensive short course with the vendor or a training partner such as GeoTrain or Global Knowledge.

- Self study using Computer Based Training (CBT) tools or books.

- Rely on existing skills from prior training or work experience.

- Participating in vendor supported certification-training programs through a tertiary, secondary or vocational education provider.

Given that certification can be obtained using any of these preparation methods it should be apparent that although a candidate has passed the online certification exam, they may not have skills that can be applied in the workplace. Generally, the intensive short courses and many of the paper based certification courses are intended as revision or "cram sessions" for individuals with existing hands-on experience.

Of concern to the industry is the emergence of so called "paper based certifications"(Rice, 2001). These candidates have little or no practical experience with the technology but manage to pass the certification exams with the aid of exam-cram materials and rote learning.

Vendor programs designed for educational institutions are one method of addressing the paper-based certifications. These programs differ from the other paths to certification as they:

- Set the learning within the industry context

- Develop concepts first principles

- Emphasise hands-on learning (Dodani, 1999) 
A weakness of certification is that it fails to communicate to employers that each of these forms of preparation is likely to have a different learning outcome even though the end result is symbolised as equivalent through the passing of a certification exam. It is also important to recognise that the certification exam is often limited because the computer based testing methodology is based on multiple-choice questions and may not measure a candidate's ability to actually perform tasks in a work environment.

\section{Integration With Existing Course Offerings}

\section{Achieving a Fit}

When considering integrating an ICT certification into an existing course, it is tempting to treat the exercise in the same way that a textbook is selected. A program is chosen that more or less fits the current course outline and reflects the instructor's perception of appropriate scope and sequence. There is rarely a perfect fit and some compromise will be necessary. With a less than ideal textbook it is possible to ignore chapters that the instructor feels are irrelevant, emphasise some sections and place less emphasis on other sections. However, with an ICT certification program the freedom to ignore a section is limited. The reasons for this are twofold:

- Students have the expectation of being able to successfully sit the certification exam and it is rare for the curriculum developers to include material that is not examinable.

- Most certification programs require that the educational institution deliver the entire course in sequence, thus ensuring a consistent product between institutions. (Cisco Systems, 2000).

Consequently, it is easier to integrate a certification program with a narrow scope and use supplementary materials to bring it up to the required scope than it is to integrate a more extensive certification program that includes material that the instructor would not normally cover.

\section{Australian National Training Authority}

For institutions that are obligated through policy or financial incentive to adopt Australian National Training Authority (ANTA) training packages, such as TAFEs and high schools, the integration issue can become complex. ANTA defines qualifications in terms of a series of required competencies. Vendors apply to ANTA have their certification "mapped" to some or all of these competencies. A single certification program is unlikely to satisfy all of the competencies required to obtain a qualification and the integration of the remaining competencies can make the course seem disjointed. The single certification program is also likely to map to competencies forming part of several different qualifications. This can be problematic if student fees are based on the number of competencies they are enrolled in. For example, the Cisco Certified Network Associate (CCNA) program satisfies some competencies in the qualifications of Certificate III Network Administration and Certificate IV Network Management. Overall, five competencies are satisfied of which only two are relevant to Certificate III and four are relevant to Certificate IV (One competency is common to both). This is more likely to be a problem for the TAFE sector where the students' focus may be on the formal qualification rather than the industry certification. High school classes will be unlikely to attempt to cover all the competencies for a Certificate. Thus certification can be seen as an immediate qualification, giving the student improved employment prospects or as a head start to one of several Certificate level options.

\section{Speed of delivery}

The development of publishing arms such as Microsoft Press and Cisco Press show education and training are profitable business units for many vendors. Vendors are conscious of the vital service their training partners provide through delivery of intensive short courses to the vendors' existing customers and the contribution to the vendors' bottom line. Most ICT certification programs developed for educational in- 
ICT Industry Certification

stitutions specify a maximum weekly contact time of typically 12 hours and a minimum course completion time. These constraints serve the dual purpose of limiting competition between the two modes of training and allow sufficient time to complete the more extensive and hands-on educational program. For educational institutions considering accelerated programs such as intensive summer units, 2-year trimester-based undergraduate degrees and 1-year intensive Masters Degrees, timetabling and compliance can become problematic.

\section{Recognition of Prior Learning}

Vendors associated with certification programs have a vested interest in ensuring that training standards are maintained. Accordingly there is usually some form of quality assurance program or curriculum delivery agreement that must be adhered to. The quality assurance program results in a consistent training product between educational providers and gives students fair preparation to sit the certification exam regardless of the institution at which they studied. Problems can arise when comparisons are made between vendor certification programs studied at differing educational tiers. For example, it is quite possible that the same Microsoft certification program is offered at both a high school and within a University. Does this mean that the high school program is equivalent to the university program? Should a student who completed a high school program be given an exemption for the university units?

There is nothing new in this dilemma. Similar situations arise for introductory information technology, accounting and economics subjects taken in upper secondary school. Often these subjects have similar course outlines and use the same texts as the equivalent university subjects. Universities will usually argue that these subjects are taught at a higher level or that additional topics are included. This argument is more difficult with industry certification programs as the materials, content and delivery are far more homogenous. Clearly expectations are higher of university students and this manifests itself in one of three ways:

- A university course can expand on the certification curriculum, delving deeper into theory and expanding on the topics.

- The assessment requirements can be made more rigorous.

- Finally, the rate of delivery can be increased.

In practice it can be difficult to seamlessly integrate additional material into an existing well-structured and on-line course offering. Similarly, it can be difficult to assess material at a higher level when built in self-assessment items are providing students with feedback on their progress. For these reasons it is more common to simply deliver the material at a faster pace to more advanced audiences. Common delivery times for the CCNA certification program are outlined in table 1 below.

When taken in context, it is not unreasonable that the same two-year internetworking certification, on

\begin{tabular}{|l|c|l|}
\hline Education Level & Typical delivery time & Educational objective \\
\hline High School year 11/12 & 2 years & $\begin{array}{l}\text { Certification and an immediate em- } \\
\text { ployment qualification. }\end{array}$ \\
\hline TAFE or University Undergraduate & 12 Months & $\begin{array}{l}\text { Certification and a component in a } \\
\text { formal Certificate, Diploma or Degree }\end{array}$ \\
\hline Postgraduate & 6-8 Months & $\begin{array}{l}\text { Introductory data communications } \\
\text { unit(s) }\end{array}$ \\
\hline
\end{tabular}

Table 1. Delivery time frames and objectives for the CCNA program in three educational contexts. 
which a high school student builds a career, can also form an introductory data communications unit for a postgraduate student when delivered at an accelerated pace. However, because the programs are so identifiable, the issue of subject equivalence will certainly be raised. To keep pace with their industry, certifications tend to have a limited lifespan. For this reason we are unlikely to see high school students seeking exemptions for a coursework Masters program featuring certification! More likely are high school student seeking exemptions from TAFE or undergraduate university units and undergraduate university students seeking exemptions from postgraduate units.

The TAFE sector has a formal Recognition of Prior Learning (RPL) policy and will recognise completion of the certification program within a high school environment. University academics and administrators will need to consider how they will treat students in this position and ensure consistency with their treatment of other IT subjects studied in high school.

\section{Obstacles to Adoption}

In addition to the structural obstacles associated with trying to integrate an ICT certification, there are several perceptual obstacles to the adoption of an ICT certification program in an educational institution.

\section{Instructor Training}

Academic staff may be reluctant to become instructors associated with the delivery of certification training. For most educators there is no requirement for further validation of their ability to teach a course after initial employment. In stark contrast, most certification programs require an instructor be certified in each module that will be taught in addition to an overall instructor certification (Cisco 2000). Furthermore, instructors are required to hold the current industry certification for the modules that they teach (Microsoft, 2000) and periodically renew their certifications. For many instructors the constant validation and embarrassing possibility of not achieving certification is reason enough to dismiss certification as a viable inclusion in their program.

\section{Vocational}

Certification programs can be perceived as too vocational for a university context. This is often the result of the evaluator focusing on the actual certification exams which tend to test memory rather than reasoning or skills (Dodani, 1999), rather than examining the course curriculum. Alternatively, individuals may have had experience with the intensive one-week training partner offerings. Certification programs designed for inclusion in mainstream educational offerings are generally broader and the certification exam requirements are merely a subset of the course. For introductory subjects at a university level, considerable time is spent learning syntax and become familiar with the technological environment, for both software and hardware. Certification programs are eminently suitable for this type of learning and often include support materials in the form of exercises and software simulators. For more advanced subjects, it is important that the certification curriculum follows up with background theory and develops a students design and problem solving skills. The curriculum varies considerably between vendors and it is wise to critically evaluate the curriculum and the planned learning outcomes when considering inclusion at higher levels within a degree program.

\section{Vendor Neutrality}

A common criticism of certification programs is that a course is no longer vendor neutral and that certification curriculum is nothing more than advertising for the vendor's product. However, even supporters of certification programs find it embarrassing using material with too strong a marketing flavour rather than an engineering or technical focus. There can be no doubt that ultimately vendors see education as a way of improving their profitability, however, there is little need for blatant advertising and propaganda within the curriculum. Students taught using the vendor's software or hardware will naturally be more familiar 
with those products and this is likely to be a far more powerful form of advertising than the need to incorporate it strongly in the curriculum. For educators that feel uncomfortable with this, consider the hardware or software platform that is currently in use and the likelihood that students will feel predisposed to using that same vendors product in the future.

If vendor neutrality is still a significant issue then one powerful approach might be to use one vendor's certification program and encourage students to compare and contrast competing technology from other vendors. This strategy might also be useful in differentiating one institution's certification program from another institution's offering.

\section{Risks}

\section{Costs}

The costs associated with the adoption of a certification program can be significant and generally fall into one of the following categories:

- Capital setup costs - The purchase of any necessary software and hardware.

- Annual maintenance - Fees associated with running the program, maintaining licenses and equipment maintenance contracts.

- Periodic equipment replacement costs for equipment oriented certifications.

- Instructor training costs.

These costs are known or can be estimated and most institutions will use these figures to perform at least a rudimentary cost benefit analysis before deciding to adopt a certification program. Less obvious costs that can be overlooked in this process include:

- Costs attributable to new delivery formats.

- Instructor training time

If the certification program places a greater emphasis on laboratory work and specifies maximum class sizes or minimum student to equipment ratios, there will be a considerable impact on teaching time and cost. Most certification programs require instructors to attend both initial and ongoing training. This can mean: significant time away from the employer; time for self-study; preparation and travel. As examples, instructor certification for the CCNA program involves an initial 20 days training and instructor training for the CCNP program requires an additional 40 days training and overseas travel.

\section{Key Man}

Any certification program that requires a significant investment in instructor training is at risk of that instructor leaving. Most vendors make allowances for this event. Microsoft and Cisco allow new instructors to teach individual modules for which they are instructor certified, even if they have not completed the entire instructor certification. In this way a new instructor can be trained as long as they stay one module in front of the students they are teaching. Cisco also allows an institution to 'borrow' an instructor from another institution but only for a period of six months. Despite these allowances the loss of an instructor will have a significant disruptive effect and a financial impact.

\section{Advanced Certifications and Adequate Student Numbers}

Advanced certifications often have prerequisite certifications that can limit enrolments. If the advanced certification does not require additional software or hardware then a small class may be viable, although 
the instructors training costs will still need to be justified. Where the advanced certification requires additional software or hardware, small classes may not be viable.

One source of students, who are candidates for advanced certification, are those already working in the ICT industry. Educational institutions can be attracted to the advanced certification market because of the high price charged by the training partners, in many cases over $\$ 3,000$ per week. However, as the ICT employer usually pays for the intensive training and the training is held during working hours there is little incentive for students to look to educational institutions as an alternative. Students already employed in the ICT industry that do choose to obtain certification through an educational institution, usually value the formal qualification that the institution offers and the opportunity to study for certification in a more learner centric mode.

Attempting to compete with training partners on the basis of price is not likely to be successful. A better strategy is to compete on the basis of value for time, conveying to potential students the benefits that quality, learning outcomes and formal qualifications offer. Admittedly this is far more difficult to convey than a simple price comparison.

\section{Marketing}

While some academics will view vendor association as an attack on independence and unbiased curriculum, others will see industry links, co-branding and exciting marketing opportunities. The risk with a close vendor tie stems from the volatility of the ICT sector. For certification curriculum that emphasises generic industry skills, the market position of the vendor should be far less important than the overall quality of the program. However, students do perceive a certifications value to be closely related to the performance of the vendor promoting the certification. To the extent that potential employers share this view, the students' valuation of the certification is understandable. For an institution that supplements a solid existing program with certification, this should not represent a problem. Educational offerings built and marketed on the basis of their certification content, however, will find themselves sharing in the ICT sector's booms and busts.

\section{Conclusion}

This paper has shown that there are many issues to be explored when contemplating the inclusion of an ICT certification within a post secondary qualification. Costs, problems of structural fit and risks can all be quantified and considered once they have been identified. However, when it comes to training, ICT vendors are market-driven and quicker to adopt new teaching paradigms than educational institutions. Whether an educational institution is prepared to adopt these changes will, ultimately, determine the viability of a certification program. Resistance to the shift from being the "sage on the stage" to the "guide on the side", a reluctance to participate in the instructor training or concerns over vendor neutrality, will quickly erode support for an otherwise exciting inclusion.

\section{References}

Australian Information Industry Association. (2001). Submission to the Senate Inquiry into the Capacity of Public Universities to meet Australia's Higher Education Needs.

Cisco Systems. (2000). Cisco Networking Academy Program Semesters 1-4 Quality Assurance Plan and Academy Operation Guide. v2.1, 11

Deloitte Touche Tohmatsu and the Australian Bureau of Statistics (2000). Market for Australia’s IT\&T Skills 2000-2002

Dodani, M. (1999). The Art of Skill Building Without Teaching. Journal of Object Oriented Programming, July/August, 48-50

Microsoft (2000). Windows 2000 Curriculum and Implementation Planning Guide for Educators.

Ray, C.M. and McCoy, R. (2000). Why Certification in Information Systems? Information Technology, Learning and Performance Journal, 18(1), 1-4 
Rice, D. (2001). IT training solutions: Filling the need for skilled employees. IT Support News, 21(6), 20-22.

\section{Bibliography}

Michael W. Dixon is a Senior Lecturer in, and program chair for, Telecommunications Management at Murdoch University. In 1998 he established Murdoch as one of the first University based Cisco Systems Networking Academies outside of the USA. He instructs in the CCNA and CCNP programs at both undergraduate and postgraduate levels and holds a PhD in communication engineering.

Terry W. Koziniec is a Lecturer in Telecommunications Management at Murdoch University. He instructs in the CCNA and CCNP programs at both undergraduate and postgraduate levels and has been engaged in CCNP curriculum development for Cisco Systems. As a doctoral student, he is examining explicit congestion notification in TCPIP networks. 